\title{
Does Student Quality Matter In The Teaching Of Economic Principles?
}

Giuliana Campanelli Andreopoulos, William Paterson University, USA Alexandros Panayides, William Paterson University, USA

\begin{abstract}
Economics is usually perceived as a difficult subject among undergraduate students and the literature suggests that the student's problems with principles of economics are mainly related to the chalk and talk type of teaching, the simplicity of economic models, limited discussions on current economic issues, and on race, gender, and other types of diversity. In previous investigations we tried to shed some light on this debate by asking directly students for their opinions on the way introductory economics is taught. In this paper we extend our previous studies, by using a larger sample and by distinguishing between the good students and the rest in order to see whether quality considerations play an important role in the results.
\end{abstract}

Keywords: Teaching Economic Principles and Student Quality

\section{INTRODUCTION AND SUMMARY OF THE LITERATURE}

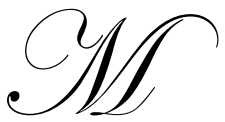

any students perceive economics as a difficult subject and this prevents them from a good performance. There is a general consensus that this is mainly due to the style and the method of teaching together with the course content Jensen and Owen (2003), Lee, Salemi and Siegfried (2002), Bartlett (1995), and Walstad and Saunders (1998). In particular, it is suggested that the chalk and talk type of teaching, the simplicity of economic models, the limited discussion on current issues, and on race, gender, and other types of diversity are the main factors responsible for this outcome, Becker (2001, 1997, \& 1996), Feiner and Roberts (2003) and Tuma (2003). When it comes to the best students, the literature seems to suggest that these students are the ones who suffer the most from this type of teaching. Researches on educational practices in general suggest that they do not like passive method like the chalk and talk and the oversimplifications of many economic models, Jensen and Owen (2003). These explanations are appealing to instructors, but we decided to verify them by asking directly the students their opinion on the way introductory economics is and should be taught. The present paper is an extension of our previous study Andreopoulos and Panayides (2008) by differentiating between the best students (with GPA equal to 3.5 and above) and the rest because we believe that the good students are very demanding on the type of teaching as well as on the course content.

\section{EMPIRICAL INVESTIGATION}

\section{Data Sample}

Our empirical investigation is based on students who attended Principles of Macroeconomics at the William Paterson University (WPU) in the period from spring 2008 to fall 2009 (four semesters) resulting in 209 responses.

In 2008, the first year of our investigation, the total number of undergraduate students was 8,741 of which 1,627 were enrolled in the college of business. The demographic data of students attending WPU can be summarized as follows: (a) Student body profile by gender: Females $55.6 \%$ and male $44.4 \%$; (b) Student body profile by ethnicity: As table 1 shows, Whites are the majority of the student body followed by Hispanics and African Americans. It is worth noting that WPU recruits almost all of its full time first year students from the state of New Jersey. 
Table 1

Enrolled Students by Ethnicity, Fall 2008

\begin{tabular}{|l|c|c|}
\hline & Number & Percentage \\
\hline African American & 1,217 & 13.9 \\
\hline Asian & 512 & 5.9 \\
\hline Hispanic/Latino & 1,581 & 18.1 \\
\hline Native American & 11 & 0.1 \\
\hline Nonresident/Alien & 78 & 0.9 \\
\hline White & 4,634 & 53 \\
\hline Unknown/Other & 708 & 8.1 \\
\hline Total & $\mathbf{8 , 7 4 1}$ & $\mathbf{1 0 0}$ \\
\hline
\end{tabular}

\section{Questionnaire}

The study was conducted by using a questionnaire, distributed to students in the classroom (the questionnaire can be found in the appendix). The first part of the questionnaire deals with the methods of teaching economic principles. In particular, we asked students to comment on the following methods of teaching: Chalk and talk type of lecture, teaching with technological tools, teaching with student interaction, a combination of all of the above, and on line courses. The second part of the questionnaire deals with current economic issues and, more specifically, we asked students whether current economic issues should be discussed at greater length in class and (in their opinion) which ones. The remaining sections of the questionnaire, parts three through six, deal with other aspects discussed in the literature such as: connections between the course and everyday life decisions, the relationship between the simplicity of economic models and the understanding of the subject, the introduction of issues such as race, gender and other types of diversity into principles courses. Finally, we asked students to offer possible suggestions on how to improve the teaching of introductory economics.

For the purpose of this investigation we report the results on four issues: chalk and talk type of lecture, the simplicity of economic models, current issues, and diversity. These are the main explanatory variables stated in the literature for the lack of interest in economics and a consequent unsatisfactory performance in the subject. The other topics will be the subject of our future investigations.

\section{Results}

First, on the chalk and talk type of lecture, the main results are presented in table 2:

Table 2

Chalk and Talk

\begin{tabular}{|l|c|c|}
\hline & Best & Rest \\
\hline & Percent & 76 \\
\hline Positive Answers & 69 & 3 \\
\hline Negative Answers & 5 & 11 \\
\hline Mixed Answers & 11 & 3 \\
\hline Unclear & 5 & 7 \\
\hline No answer & 10 & \\
\hline
\end{tabular}

The overwhelming majority of students, approximately 73 per cent, like the chalk and talk type of teaching. However, the best students like it slightly less than the rest. From the qualitative answers we can infer that the main reason for this result is that students are able to follow and have a better understanding of the material mainly because it is presented in a concise matter. Nevertheless, it is worth adding that several of the best students stated that this method can be boring. On this issue we should add that the data show a strong correlation between boring classes and "boring professors" since the boringness drops in the case of instructors who have the reputation of being very lively. One may say that the instructor also plays an important role for this result. Thus our investigation does not seem to confirm the literature according to which the chalk and talk method of teaching is assumed to be 
very boring. The reality is more complex than the simplistic assumptions of the literature and the reputation of the instructor also needs to be considered.

We also asked students whether they think that the simplicity of economic models renders their understanding of economics easier. The results are summarized in table 3.

Table 3

Simplicity of Economic Models

\begin{tabular}{|l|c|c|}
\hline & Best & Rest \\
\hline & Percent & 71 \\
\hline Positive Answers & 90 & 11 \\
\hline Negative Answers & 2.5 & 9 \\
\hline Mixed & 2.5 & 0 \\
\hline Unclear & 0 & 9 \\
\hline No Answer & 5 & \\
\hline
\end{tabular}

Our data show that more than 80 per cent of the students like the simplicity of economic models and consider it very effective. The percentage of positive answers among the best students is exceptionally high, 90 per cent. The main reason for this result is that the students find the simplicity of the model and its graphical representation very helpful to grasp immediately the economic meaning. Once again, these results contradict the literature which emphasizes the simplicity of economic models as a negative element for students' interest and learning, Becker (2001).

We also asked students whether or not current economic issues should be discussed at greater length in class. The results are summarized in table 4.

Table 4

Longer Discussion on Current Economic Issues

\begin{tabular}{|l|c|c|}
\hline & Best & Rest \\
\hline & Percent & Percent \\
\hline Positive Answers & 54 & 55 \\
\hline Negative Answers & 27 & 26 \\
\hline Mixed Answer & 12 & 7 \\
\hline Unclear & 0 & 7 \\
\hline No answer & 7 & 5 \\
\hline
\end{tabular}

Our results show that more than half of the student's population, approximately 55 per cent, would like to have longer discussion on current issues, particularly on unemployment, recession and the current financial crisis. This time our results seem to confirm the literature but the support is weak. From the qualitative data, combining the negative and the mixed answers, a high percentage of students, 35 per cent, seem to be unwilling to expand the discussion on current issues. The main reason for this result is that in some macroeconomic classes, current issues are extensively discussed by the instructor as part of the course content. This means that the need for longer discussions on current economic issues cannot be considered independently of the course content and the emphasis the instructor already gives to them. To support this conclusion we recall that in a previous investigation we found that microeconomic students are more willing to discuss current issues than the macro students, Andreopoulos and Panayides (2008).

Finally, we asked students whether issues about race, gender and other types of diversity should receive greater attention in the class. The results are summarized in table 5 . 
Table 5

Greater Attention to Race, Gender and Other Types of Diversity

\begin{tabular}{|l|c|c|}
\hline & Best & Rest \\
\hline & Percent & 24 \\
\hline Positive Answers & 20 & 59 \\
\hline Negative Answers & 68 & 11 \\
\hline Mixed Answer & 7 & 1 \\
\hline Unclear Answer & 0 & 5 \\
\hline No Answer & 5 & \\
\hline
\end{tabular}

Given our students ethnicity, it is a surprise to find that they do not like greater discussion on issues like gender, race and other types of diversity. The negative answers are astonishingly high in the case of best students, almost seventy percent. The qualitative data show that student's expectations are mostly related to business/technical type of course. One of the best students bluntly stated "this is economics, not sociology". Thus our data once again does not support the literature and the reason is because the students have different expectations from the ones the literature assumes.

\section{CONCLUSIONS}

In this paper we extended our previous investigation on teaching introductory economics by asking macroeconomic students for their opinions on the following issues: chalk and talk type of teaching, the simplicity of economics models, extended discussion on current economic issues, and greater attention to race, gender and other types of diversity. Our results are very different from those stated in the literature. The students, the best as well as the rest, all like the chalk and talk type of teaching, the simplicity of economic models and they don't like any additional discussion on gender, race and diversity. However, several of the best students stated that the chalk and talk can be boring, depending on the instructor. Thus, the type of instructor also plays a crucial role for this result. The only result which confirms the literature is longer discussion on current economic issues. However, the support for this result appears to be weak and needs to be correlated to the material discussed by the individual instructor as a part of the course content.

Quality considerations do not affect the content of the results but only the extent of their validity. In particular, in the case of the simplicity of economic models, we have an overwhelming positive answer among the best students, 90 per cent of them like it and consider it a very effective teaching method. In addition, the best students overwhelmingly dislike additional discussion on gender, race and other types of diversity. Thus, the next question then is: Why should we assume that the best students don't like simplification of models and topics?

\section{AUTHOR INFORMATION}

Dr. Giuliana Campanelli Andreopoulos earned her Ph.D. from Cambridge University in 1990 and she is currently a Professor of Economics and the Director of Experiential Learning at William Paterson University.

Dr. Alexandros Panayides earned his Ph.D. from Binghamton University (SUNY Binghamton) in 2000 and he is currently an Associate Professor and the Chairperson of the Department of Economics, Finance and Global Business at William Paterson University.

\section{REFERENCES}

1. Andreopoulos, G., and A. Panayides (2008). Teaching Economics to Undergraduates: What are the Problems? International Journal of Education Research. Vol. 3 (1), 2008.

2. Bartlett, R. L. (1995). Attracting "Otherwise Bright Students" to Economics 101. American Economic Review, 85, 362-366.

3. Becker, W. E. (2001). How to Make Economics the Sexy Science. The Chronicle of Higher Education, B10-B12. 
4. $\quad$ Becker, W. E. (1997). Teaching Economics to Undergraduates. Journal of Economic Literature, 35, 13471373.

5. Becker, W. E., \& Watts, M. (1996). Chalk and Talk: A National Survey on Teaching Undergraduate Economics. American Economic Review, 86, 448-453.

6. Feiner, S., \& Roberts, B. (1995). Using Alternative Paradigms to Teach About Race and Gender: A Critical Thinking Approach to Introductory Economics. American Economic Review, 85, 367-371.

7. Jensen, J. E., \& Owen, A. (2003). Appealing to Good Students in Introductory Economics. Journal of Economic Education, 32, 299-325.

8. Lee, W. H., Salemi, M. K., \& Siegfried, J. J. (2002). Promoting Economic Literacy in the Introductory Economics Courses. American Economic Review, 92, 463-472.

9. Siegfried, J. J. (2003). Trends in Undergraduate Economics Degrees, 1991 to 2002. Journal of Economic Education, 34, 291-294.

10. Siegfried, J. J. (2002). Trends in Undergraduate Economics Degrees, 1991 to 2001. Journal of Economic Education, 33, 291-294.

11. Siegfried, J. J., \& Round, D. (2001). International Trends in Economics Degrees During the 1990s. Journal of Economic Education, 32, 203-218.

12. Tuma, E. H. (1995). Macroeconomics and Discrimination in Teaching. American Economic Review, 85, 352-356.

13. Vascellaro, J. E. (2005). The Hot Major for Undergrads is Economics. The Wall Street Journal, July $5^{\text {th }}$.

14. Walstad, W. B., \& Saunders P. (1998). Teaching Undergraduate Economics: A Handbook for Instructors. New York: McGraw Hill. 


\section{APPENDIX}

Questionnaire

1. Personal Data

(a) Gender

(b) Student status

(c) Overall GPA

2. Comment on the following methods of teaching Economic Principles

(a) Chalk and talk type of lecture

(b) Teaching with technological tools

(c) Teaching with student interaction

(d) A combination of (a) - (c)

(e) On line courses

3. Should current economic issues be discussed at greater length in class and in your opinion which ones?

4. Do you see any connections between this course and your everyday life decisions?

5. Do you think the simplicity of models (graphical approach) renders your understanding of economics easier?

6. Do you think that issues about race, gender and other types of diversity should receive greater attention in the course?

7. What would you suggest to improve the teaching of Introductory Economics? 